Classification

Physics Abstracts

$62.20-68.25-68.48$

\title{
Mechanical behaviour of metal-ceramic bonds
}

\author{
D. Tréheux, P. Lourdin, V. Guipont and D. Juvé
}

Laboratoire Matériaux-Mécanique Physique, URA 447, Ecole Centrale de Lyon, B.P. 163, 69131 Ecully Cedex, France

(Recelved 28 February 1994, accepted 20 June 1994)

\begin{abstract}
Résumé. - Le comportement mécanique des liaisons céramique-métal est analysé du point de vue mécanique (mécanique de la rupture interfaciale, champs des contraintes appliquées et résiduelles) et, du point de vue physicochimique, en tenant compte des effets de fragilisation induits par les réactions interfaciales ou la diffusion du métal dans la céramique et des endommagements dus aux modifications de la microstructure interfaciale (segrégation, phases et films interfaciaux, microfissures...) intervenant lors de l'assemblage ou du service. En effet le comportement des assemblages métal-céramique dépend obligatoirement de la synthèse de tous ces paramètres.
\end{abstract}

\begin{abstract}
The mechanical behaviour of ceramics bonded with metal is analyzed from the mechanical point of view (interfacial fracture mechanics, applied and residual stress field) and from the physico-chemical point of view taking into account the embrittlement induced by interfacial reactions or diffusion of metal into ceramic and the damages due to the change in interfacial microstructure (segregation, interfacial phases or films, microcracks, ...) during bonding or life. Indeed the behaviour of metal-ceramic bonds is inevitably dependent on the synthesis of all those parameters.
\end{abstract}

\section{Introduction.}

Modern engineering materials and structures (for electrical or mechanical applications) often contain a metallic alloy bonded to a ceramic. Various techniques for joining ceramic to metal are available [1]. Some need an intermediate liquid phase (brazing, thermal spraying, direct bonding) and other are performed by solid state (solid state bonding, co-sintering.. ). In all cases four problems have to be overcome:

i) morphological adaptation of the surfaces in contact;

ii) formation of bonds: van der Waals bonds, chemical bonds by simple recovery of the molecular orbitals or by chemical reaction. In the last case new phases are grown at the interface :

iii) strict control over the residual stresses developed in both materials ;

iv) changes in mechanical properties of metallic alloy and ceramic close to the interface. 
Mechanical aspects are essential for points 3 and 4 and for the point 1 in the case of the solid state bonding $[2,3]$.

The purpose of this paper is to analyse those mechanical aspects of a metal-ceramic junction in connection with the chemical and physical properties.

\section{Fracture of bimaterials : interfacial fracture energy.}

Metal-ceramic interfaces exhibit a singular behaviour towards fracture because the crack can take different propagation paths [2] :

- along the interface where it is either trapped (adhesive fracture) or from where it can deviate into the adjacent bulks (mixed fracture);

- in the bulk of metal or ceramic (cohesive fracture).

1.1 INTERFACIAL FRACTURE ENERGY. - The fracture of bimaterials generally occurs by a mixed mode that includes opening (mode I) and shear (mode II) displacements of the interface crack, because of mismatch in the elastic properties of both materials (4). The parameter which measures the mixity of shear to opening at the interface crack surface is the angle of loading $\Psi[5]$ defined as :

$$
\Psi=\operatorname{Arctan}\left(K_{2} / K_{1}\right)
$$

where $K_{1}$ and $K_{2}$ are respectively the stress-intensity factor in opening and shear modes.

If $\Psi=-\pi / 2$ or $+\pi / 2$, the crack propagation is induced by a pure shear mode.

If $\Psi=0$ the crack propagates by an opening mechanism.

The fracture is mixed if $0<\Psi<\pi / 2$ or $-\pi / 2<\Psi<0$.

The energy $G$ dissipated during the propagation (per unit surface of crack) is connected to $K_{1}$ and $K_{2}$ by :

$$
G=\left(1 / \bar{E}_{\mathrm{c}}+1 / \bar{E}_{\mathrm{m}}\right)\left(K_{1}^{2}+K_{2}^{2}\right) / 2 \cosh ^{2} \pi \varepsilon
$$

where $\bar{E}=E /\left(1-\nu^{2}\right)$

$$
(E=\text { Young's modulus }, \quad \nu=\text { Poisson's ratio, } \quad c=\text { ceramic }, \quad \mathrm{m}=\text { metal })
$$

and

$$
\varepsilon=\ln \{(1-\beta) /(1+\beta)\} / 2 \pi
$$

$\beta$ is a parameter function of $\mu$ (shear modulus) and $\nu$ for both materials, defined by

$$
2 \beta=\left\{\mu_{\mathrm{c}}\left(1-2 \nu_{\mathrm{m}}\right)-\mu_{\mathrm{m}}\left(1-2 \nu_{\mathrm{c}}\right)\right\} /\left\{\mu_{\mathrm{c}}\left(1-\nu_{\mathrm{m}}\right)+\mu_{\mathrm{m}}\left(1-\nu_{\mathrm{c}}\right)\right\} .
$$

This corresponds to a generalization of the Irwin approach [6].

Generally $\varepsilon$ is small and consequently the interfacial fracture-mechanics is only developed for $\varepsilon=0$ [7].

The interfacial energy $G_{\mathrm{c}}$ corresponds to the critical value of $G$ when the crack remains at the interface. It depends not only on the thermodynamic work of adhesion $E_{\text {ad }}$ (Young-Dupre energy) but also on physical phenomena (plastic deformation, friction, dielectric polarization.. ) appearing near the tip of the crack. In this way:

$$
G_{\mathrm{c}}=E_{\mathrm{ad}}+\Phi\left(E_{\mathrm{ad}}\right)
$$

where $\Phi\left(E_{\mathrm{ad}}\right)$ represents the whole dissipated energies $(8,9)$. 
Moreover, since $G$ is a function of $K_{1}$ and $K_{2}, G_{\mathrm{c}}$ is dependent on $\Psi=\operatorname{Arctan}\left(K_{2} / K_{1}\right)$ as shown in figure 1 [8].

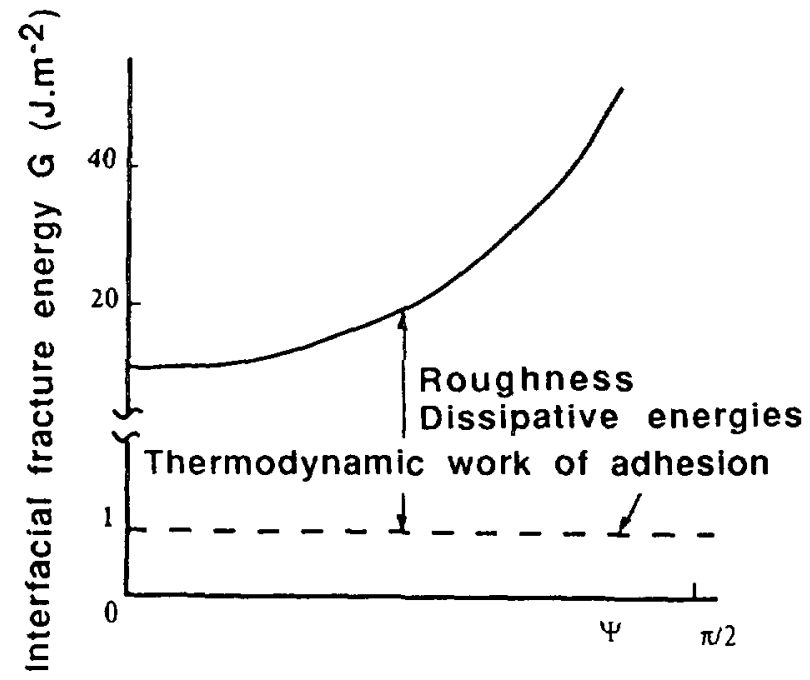

Fig. 1. - Variation of the interfacial fracture energy is. $\Psi$ (from [10]).

The roughness near the crack-tip is schematized in figure $2[4,11]$. The contact asperities inhibit the crack-growth by friction and bridging. The length of the contact area $D$ (Fig. 2) and thus the magnitude of the bridging is a function of :

- the friction coefficient $\mu$

- $\Psi$;

- $\theta=E H^{2} / L G_{0}$ (Fig. 2) ;

where $G_{0}$ is the fracture energy for $\Psi=0$.

When $\Psi=0$ or $\chi=0$, then $D=0$ and the crack is not bridged by the roughness.

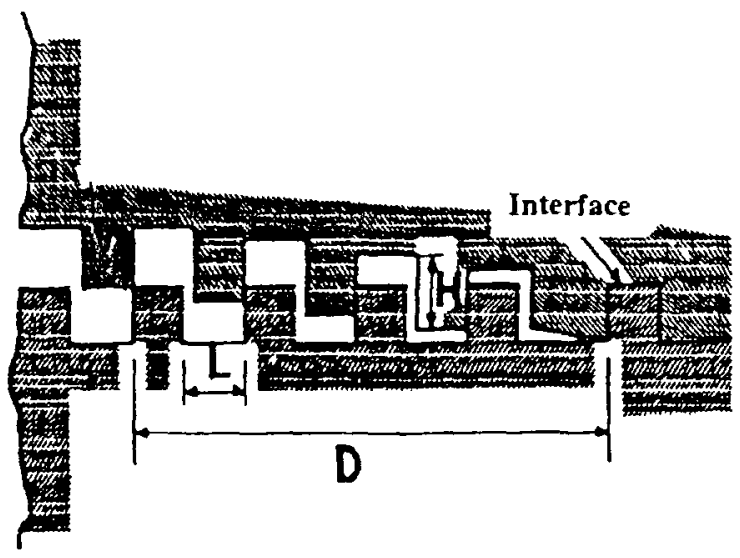

Fig. 2. - Schematic representation of the roughness of the interface crack near the tip (from [18]). 
When $\Psi \neq 0$ and $\chi \neq 0$, crack-bridging can occur and depends on $\Psi, \chi, \mu$ and on the roughness morphology $[4,11]$.

Finally, the fracture energy $G_{0}$ measured for $\Psi=0$ corresponds to the fracture of chemical bonds without roughness contribution. The fracture energy measured when $0<\Psi<\pi / 2$ is higher and includes a mechanical effect. The dependence of $G$ on $\Psi$ should then be known in order to characterize a metal-ceramic interface.

Different mechanical tests are available allowing an investigation of the interface fracture energy over a wide range of $\Psi$ (Fig. 3 ).

1. Peel test

G depends on film properties

2. Delamination specimen

$$
\begin{gathered}
\mathrm{M}=\mathrm{Pl} / 2 \mathrm{~b} \\
\mathrm{~b}^{2} \mathrm{H}^{3} \mathrm{EG} / \mathrm{P}^{2} \mathrm{l}^{2}=\mathrm{k}(\mathrm{h} / \mathrm{H}) \\
\Psi=\mathbf{5 0 ^ { \circ }}
\end{gathered}
$$

3. Pull out test

$\mathrm{GE} / \mathrm{s}^{2} \mathrm{R} \approx 0.25$

$70^{\circ} \leq \Psi \leq 90^{\circ}$
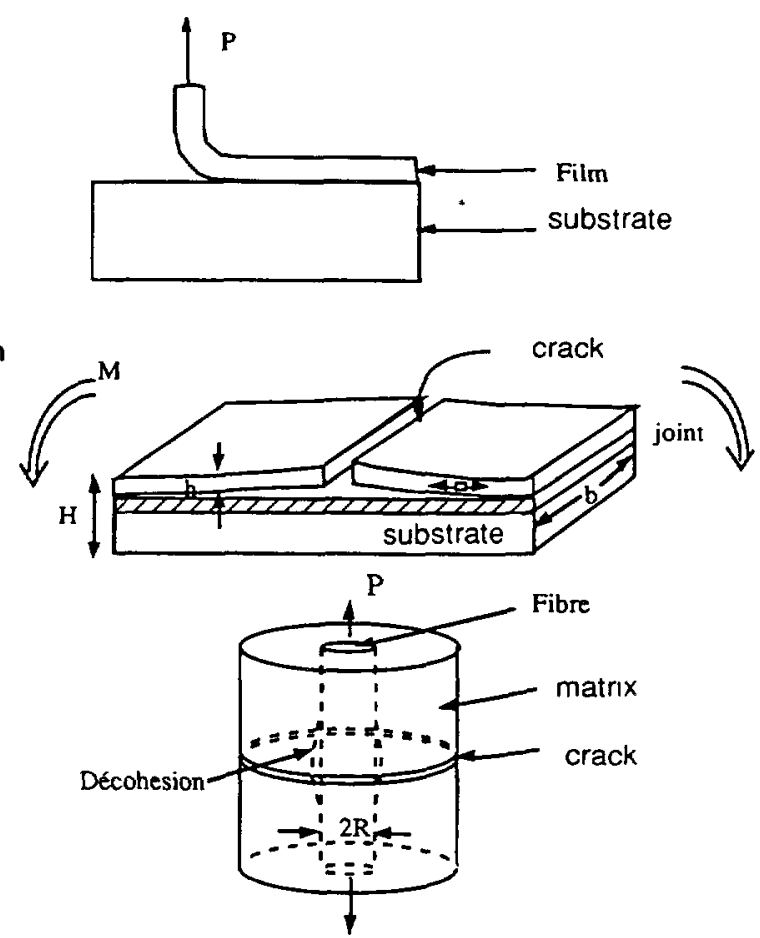

\section{Double cantilever beam specimen (DCB) \\ $b^{2}$ hEG $/ P^{2}=$ $12(a / h)^{2}[1+(2 /)(h / a)]^{2}$ \\ $0 \leq \Psi \leq 5^{\circ}$}

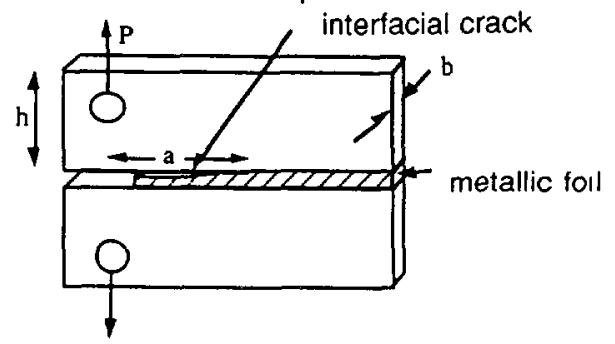

\section{Single edge notched beam specimen (SENB)}

$4 b^{2} w^{4} E G / 9 P^{2}(L-1)^{2}=$

a $(1.99-2.47 \mathrm{a} / \mathrm{w}+12.97$

$\left.(\mathrm{a} / \mathrm{w})^{2}\right)^{2}$

$0 \leq \Psi \leq 5^{\circ}$

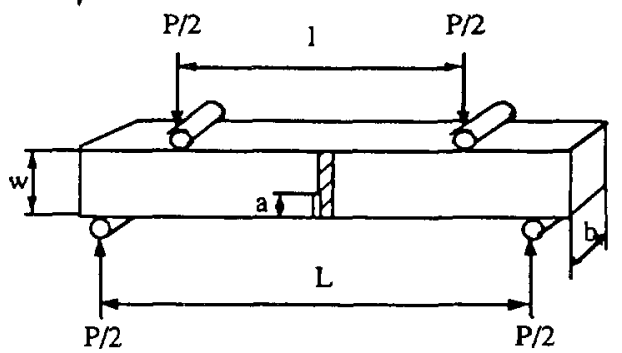

Fig. 3. - Schematic representation of some tests used to measure the interfacial fracture energy. 
1.2 COHESIVE FRACTURE. - When the interfacial fracture energy is equal or greater than the fracture energy of the constituant materials, the crack can deviate and grow $[12,13]$ :

- either into ceramic, by a brittle mechanism (mode I) : the crack propagation depends on the defects and on the residual stresses close to the interface :

- or into metal : a ductile fracture being favoured when the yield strength of the metal is small [14] and the metallic foil is thin [13] or presents defects in the bulk.

1.3 EXPERIMENTAL EXAMPLES. - Four points bending samples have been solid-state-bonded to measure the nickel/alumina interfacial fracture energy $[2,15]$ using the method proposed by Charalambides [16]. Two different phase angles of loading $\Psi$ have been chosen: $\Psi<5^{\circ}$ (SENB specimens, Fig. 3) and $\Psi=42^{\circ}$ (delamination specimens, Fig. 3) (Tab. I).

Table I. - $\mathrm{Ni}-\mathrm{Al}_{2} \mathrm{O}_{3}$ interfacial fracture energy for various bonding temperature (4 MPa, time $=0$ ).

\begin{tabular}{|c|c|c|c|}
\hline Température $\left({ }^{\circ} \mathrm{C}\right)$ & $\Psi\left({ }^{\circ}\right)$ & $G_{\mathrm{c}}\left(\mathrm{J} . \mathrm{m}^{-2}\right)$ & Test specimen \\
\hline 1050 & 42 & 6 & delamination \\
1100 & $2 / 42$ & $10 / 31$ & SENB/delam \\
1150 & $2 / 42$ & $41 / 33$ & SENB/delam \\
1180 & 2 & 31 & SENB \\
1190 & 42 & 32 & delamination \\
1200 & 2 & 41 & SENB \\
1210 & $2 / 42$ & $42 / 32$ & SENB/delam \\
1250 & $2 / 42$ & $50 / 34$ & SENB/delam \\
\hline
\end{tabular}

For an optimal bonding, obtained at $1300^{\circ} \mathrm{C}$ under $4 \mathrm{MPa}$ during $5 \mathrm{~h}$, the fracture is always cohesive within alumina and the fracture energy is equal to $50 \mathrm{~J} . \mathrm{m}^{-2}$, that corresponds to the bulk alumina fracture energy.

$\mathrm{Ni}-\mathrm{Al}_{2} \mathrm{O}_{3}$ joints fabricated in the range $1150{ }^{\circ} \mathrm{C}-1300{ }^{\circ} \mathrm{C}$ under $4 \mathrm{MPa}$, without any temperature plateau, fail exclusively in the interface, the fracture energy being about $40 \mathrm{~J} . \mathrm{m}^{-2}$. The fracture energy for interfaces fabricated below $1100^{\circ} \mathrm{C}$ decreases rapidly to about $10 \mathrm{~J} \cdot \mathrm{m}^{-2}$ at $1050^{\circ} \mathrm{C}$. Whatever the processing conditions, the measured fracture energies are always much larger than the $\mathrm{Ni}_{-} \mathrm{Al}_{2} \mathrm{O}_{3}$ ideal thermodynamic work of adhesion $\left(E_{\mathrm{ad}}=1.2 \mathrm{~J} \cdot \mathrm{m}^{-2}\right)$ [17] indicating that the dissipative energy caused particularly by the plastic deformation of the metal is the major contribution to the total fracture energy.

The minimum temperature needed to obtain strong bonds was found to be about $1150^{\circ} \mathrm{C}$. It seemly corresponds to the growth of an interfacial film, rich in magnesium, stemming from the intergranular phase of alumina $[2,15]$. Further investigations are in progress to investigate this mechanism.

To conclude, table II collects some results obtained for other metal-ceramic systems and confirms :

- interfacial fracture energies are always much greater than the thermodynamic work of adhesion ;

- a low yield strength of metal induces a higher dissipated energy during fracture, by plastic deformation, and thus a higher fracture energy.

Moreover real interfacial fracture energies, higher than the fracture energy of ceramic, are difficult to measure because of the presence of defects and residual stresses in ceramic, near by the interface, which deviate the crack to ceramic bulk. 
Table II. - Interfacial fracture energy $G_{\mathrm{c}}$ and thermodynamic work of adhesion $E_{\mathrm{ad}}$.

\begin{tabular}{|c|c|c|c|c|}
\hline System & $\Psi\left(\left(^{\circ}\right)\right.$ & $G_{\mathrm{c}}\left(\mathrm{J} \cdot \mathrm{m}^{-2}\right)$ & $E_{\mathrm{dd}}\left(\mathrm{J} \cdot \mathrm{m}^{-2}\right)$ & Test \\
\hline $\mathrm{Cu} / \mathrm{SiO}_{2}$ & 5 & $1-10[18]$ & $0.200[20]$ & DCB \\
\hline Pt/Sapphire (0001) & 50 & $40+-4[18]$ & $1.035[21]$ & delamination \\
\hline $\begin{array}{l}\mathrm{Nb} / \mathrm{Al}_{2} \mathrm{O}_{3} \\
\mathrm{Nb} / \mathrm{Al}_{2} \mathrm{O}_{3} \\
\text { sputter cleaned } \\
\text { U.H. Vacuum }\end{array}$ & $\begin{array}{l}5 \\
5\end{array}$ & $\begin{array}{l}80+-30[18] \\
110+-5[23]\end{array}$ & $\begin{array}{l}2[22] \\
2[22]\end{array}$ & $\begin{array}{l}\text { SENB } \\
\text { SENB }\end{array}$ \\
\hline Au/Sapphire (0001) & 50 & $30-60[19]$ & $0.265[17]$ & delamination \\
\hline $\begin{array}{l}\mathrm{Cu} / \mathrm{Al}_{2} \mathrm{O}_{3} \\
\text { sputter cleaned } \\
\text { U.H. Vacuum }\end{array}$ & 5 & $160+-15[23]$ & $0.5 \quad[17]$ & SENB \\
\hline
\end{tabular}

\section{Role of the stress fields.}

2.1 APPLIED STRESSES. - Evans et al. [12,13] have calculated the distribution of the stresses in the ceramic in the absence of thermal mismatch between the two materials. The geometry consists of a thin metal bond between two ceramics and the Young's modulus of the metal being substantially less than that of ceramic. Figure 4 shows the $\sigma_{11}$ contours near the interface obtained for $\sigma=2 \sigma_{0}\left(\sigma\right.$ applied stress, $\sigma_{0}$ yield strength of the metal). High tensile stresses are observed near the corner of the junction which can induce fracture into the ceramic body.
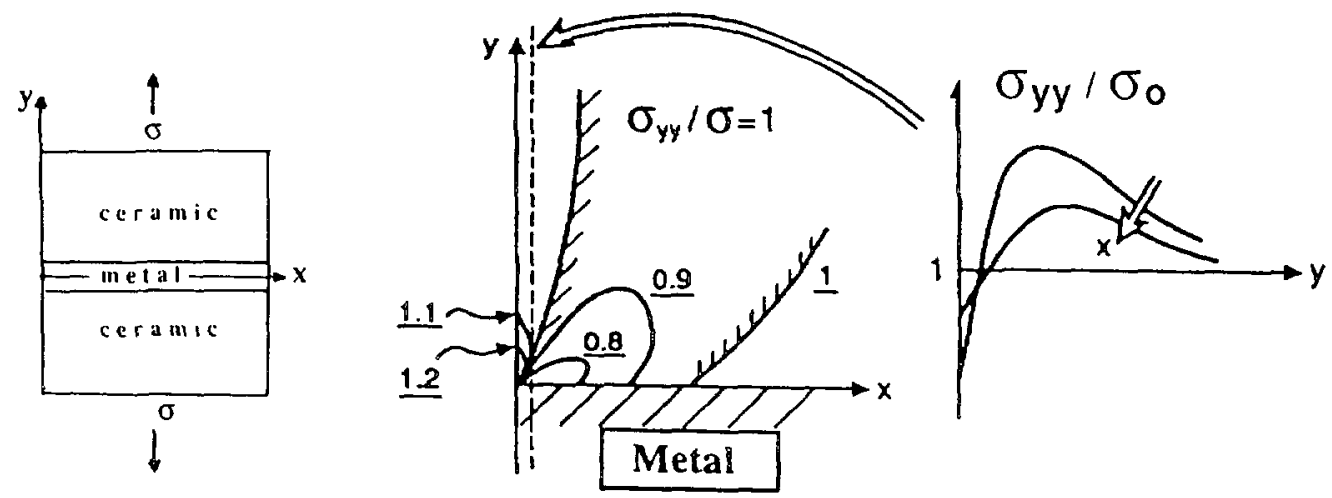

Fig. 4. - Applıed stress field near the metal-ceramic interface [13].

2.2 RESIDUAL STRESSES. - A mismatch in thermal expansion coefficient generates residual stresses in the bond. Generally the metal has the larger thermal expansion coefficient and the expansion mismatch then induces tensile stresses in the ceramic adjacent to the interface [13] as shown in figure 5 . Elsewhere the ceramic is compressed. 


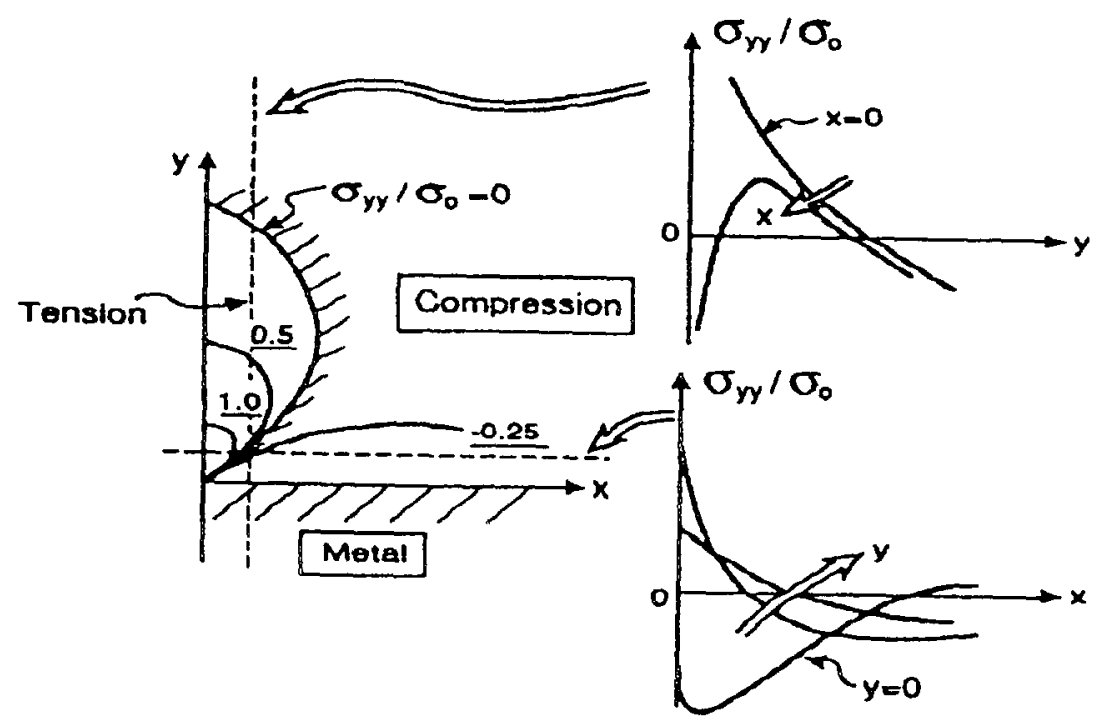

Fig. 5. - Residual stress field near the metal-ceramic interface (geometry of the Fig. 4) [13].

The superimposing of applied and residual stresses gives the true stress field in the bimaterial subject to a mechanical sollicitation. When the bond has a sufficiently high interfacial fracture energy, failure can be initiated or deviated in the ceramic, near the interface, because of the stress concentration described in figure 5 . Then the angle $\beta$ (Fig. 6) between crack and interface, at initiation, generally corresponds to an opening mode I (without mode II) [2].

The residual stresses depend on the geometry and increase with [2]:

- the size of the specimens $[24,25]$;

- the difference $\Delta T$ between bonding and room temperatures $[26,27]$ :

- the yield strength, thickness and workhardening of the metal $[24,28,29]$ (that inhibites the plastic deformation of metal):

- the mismatches in mechanical and thermal properties of both materials [30].

2.3 EXPERIMENTAL RESUlTS. - The localization of tensile and compressive stresses in the case of a solid state bonded $\mathrm{Ni} / \mathrm{Al}_{2} \mathrm{O}_{3}$ system $[2,15]$ has been investigated using numerical
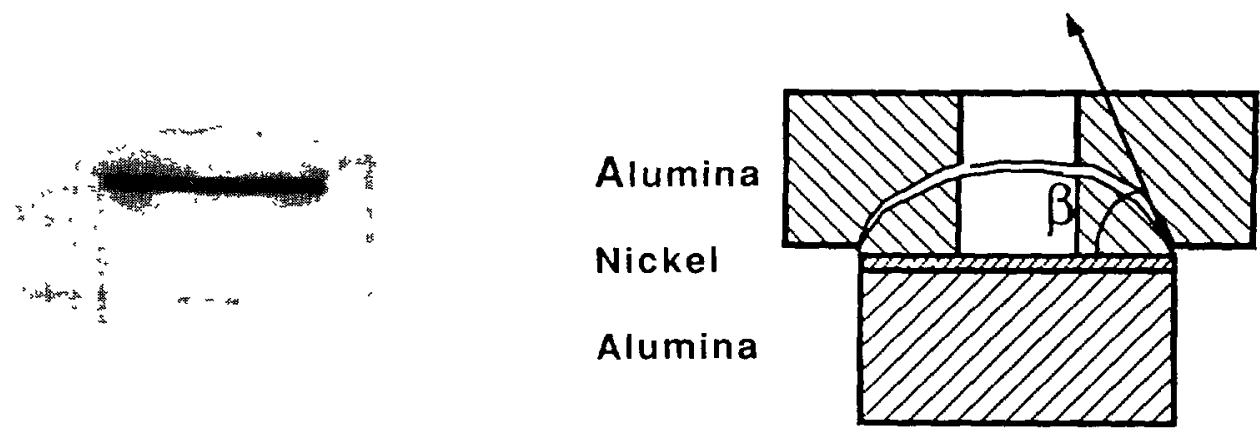

Fig. 6. - Trajectory of the crack after fracture $\left(\mathrm{Ni} / \mathrm{Al}, \mathrm{O}_{3}\right.$ push test specimen) [2]. 
simulations (finite element -Sysweld soft from Framasoft Lyon). To simulate cooling, a decrease in temperature from $1200^{\circ} \mathrm{C}$ to $20^{\circ} \mathrm{C}$ is imposed on the bond. To avoid the effect of a thermal gradient, at each step of time a uniform temperature is also imposed at every node of the mesh. Mechanical calculations take into account:

- the mismatch in thermal expansion coefficient between nickel and alumina;

- the evolution of the mechanical characteristics of the two materials with temperature.

Figure 7 shows the mesh and geometry used to conduct the calculation (elasto-plastic model) and the resulting stress fields :

- $\sigma_{11}$ tensile stresses (Fig. 7a) are located in nickel and tend to decrease near the edge of the bond. According to their intensity and localization they probably do not affect the mechanical strength of the bond;

- shear stresses $\left(\sigma_{11}\right)$ (Fig. 7c) are weak and maximum in an area located near by the interface, at the edge of the bond;

- $\sigma_{y v}$ stresses (Fig. 7b) exhibit a high tensile zone in the alumina at $0.1 \mathrm{~mm}$ far from the interface. This layer can induce brittle fracture into ceramic as shown in figure 6.

An analytical calculation based on deformation mechanism maps [31] (creep model) showed. for the same system and geometry, that tensile stresses located in nickel are lower
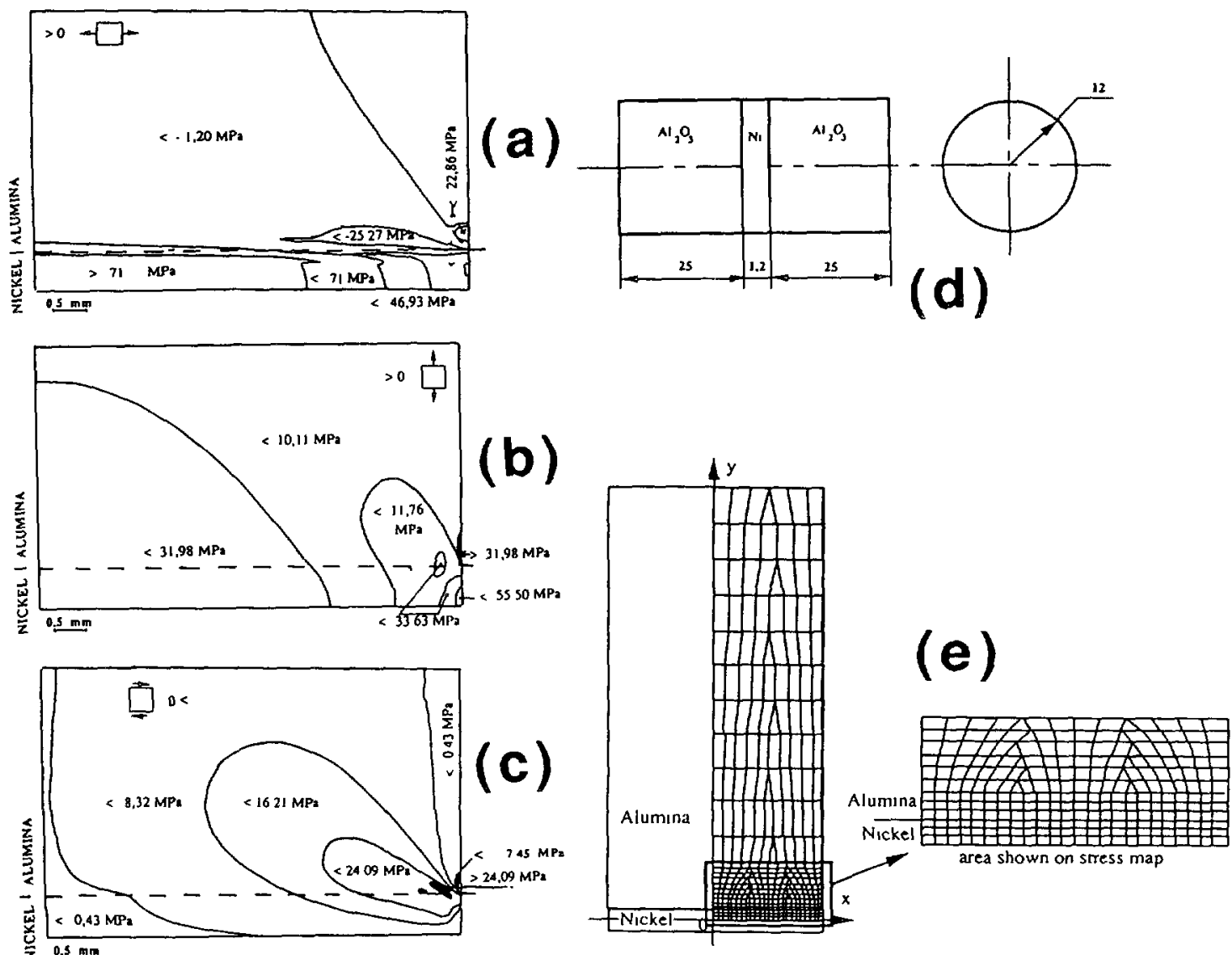

Fig. 7. - Maps of the residual stress field near the $\mathrm{N}_{1} / \mathrm{Al}_{2} \mathrm{O}_{2}$ interface. a) $\sigma_{11}$ stresses. b) $\sigma_{11}$ stresses. c) $\sigma_{11}$ stresses. f) geometry. e) finite element mesh. 
than those simulated by finite element (respectively $30 \mathrm{MPa}$ for creep model and $70 \mathrm{MPa}$ for elastoplastic model). Consequently, the maps obtained by finite element have to be quantitatively corrected. hence the necessity to perform residual stresses measurements particularly by X-ray diffraction.

Direct experimental measurements of residual stresses have been performed on a brazed assembly $\mathrm{Si}_{3} \mathrm{~N}_{4} /$ reactive solder/steel (cylindric geometry $\Phi=30 \mathrm{~mm}$, ceramic $1 \mathrm{~mm}$ thick. steel $10 \mathrm{~mm}$ thick) by X-ray diffraction (Tab. III).

Table III. - X-ray residual stress analysis parameters.

\begin{tabular}{|l|l|}
\hline Material & $\beta-\mathrm{Si}_{3} \mathrm{~N}_{4}$ \\
X-rays & $\mathrm{K}_{\alpha} \mathrm{Cu}$ \\
Diffraction planes & $(323)$ \\
Bragg angle & $141.72^{\circ} 2 \Theta$ \\
penetration depth & $40 \mu \mathrm{m}$ \\
irradiated area & $1 \mathrm{~mm}$ diameter \\
Young modulus & $274 \mathrm{GPa}$ \\
Poisson's ratio & 0.26 \\
$\Psi$ angles & $-45^{\circ}$ to $+45^{\circ}$ step $4.5^{\circ}$ \\
\hline
\end{tabular}

The trend in stresses $\left(\sigma_{11}, \sigma_{y v}\right)$, parallel to the interface at different depth from the free ceramic surface to the metal-ceramic interface, is shown in figure 8 . It is obtained after cautious abrasions causing negligeable residual stresses (grinding then polishing) and simultaneously controlled by deformation gauges. Figure 8 a gives the stresses directly measured in the central area ( $\sigma_{11}$ and $\sigma_{11}$ are continuously equal) and figure $8 \mathrm{~b}$ the corrected (by an elastic model) $\sigma_{11}$ stresses, into account the relaxation of the stresses at the time of abrasions, showing that the absolute value is lowered. Indeed, the $\varepsilon=f\left(\sin ^{2} \Psi\right)$ curves for positive and negative $\Psi$ angles are perfectly linear. In conclusion, the stress field parallel to the interface, in the central area is isotrope, biaxial and compressive. Such a stress field can improve the mechanical properties of the assembly.

Other results have been obtained by Colin [25] for alumina $(6 \mathrm{~mm}$ thick, $22 \mathrm{~mm}$ diameter)/Inconel $600(73 \% \mathrm{Ni}, 16.25 \% \mathrm{Cr}, 9 \% \mathrm{Fe}, 0.5 \mathrm{~mm}$ thick, $22 \mathrm{~mm}$ diameter $)$ bonded by Hot Isostatic Pressing. X-ray diffraction measurements, performed on the alumina surface, along two generatrixes (whitout abrasion) are given in figure 9 and show a good agreement with the results obtained by finite elements calculations.

\section{Evolution of materials near the interface.}

3.1 Embrittlement of THE CERAmic. - The problem of residual stresses is all the more important as the ceramic is often embrittled during the bonding.

This embrittlement can be due to chemical reaction between alloying elements and ceramic, giving growth to brittle phases at interface and/or cracks in ceramic. In this way the reactive brazing using $\mathrm{Ti}$ additions often conducts to this phenomenon. For example, by joining $\mathrm{Al}_{2} \mathrm{O}_{3} / \mathrm{TA} 6 \mathrm{~V}$ with a $\mathrm{CuAgTi}$ brazing alloy at $880^{\circ} \mathrm{C}(15 \mathrm{~min})$, Peytour [32] has shown the formation of various phases $\left.\left(\mathrm{Cu}_{2} \mathrm{Ti}_{4} \mathrm{O} \text {, ( } \mathrm{TiAl}\right)_{3} \mathrm{Cu}, \mathrm{Ti}_{2} \mathrm{Cu}, \mathrm{TiCu}, \mathrm{Ti}_{3} \mathrm{Cu}_{4}\right)$ at the interface and at the same time, the penetration of copper in alumina (by microprobe analysis) to a depth of $200 \mu \mathrm{m}$ which can be only explained by the penetration of copper along alumina microcracks given the negligeable solubility of copper into alumina and its diffusion kinetics (the 

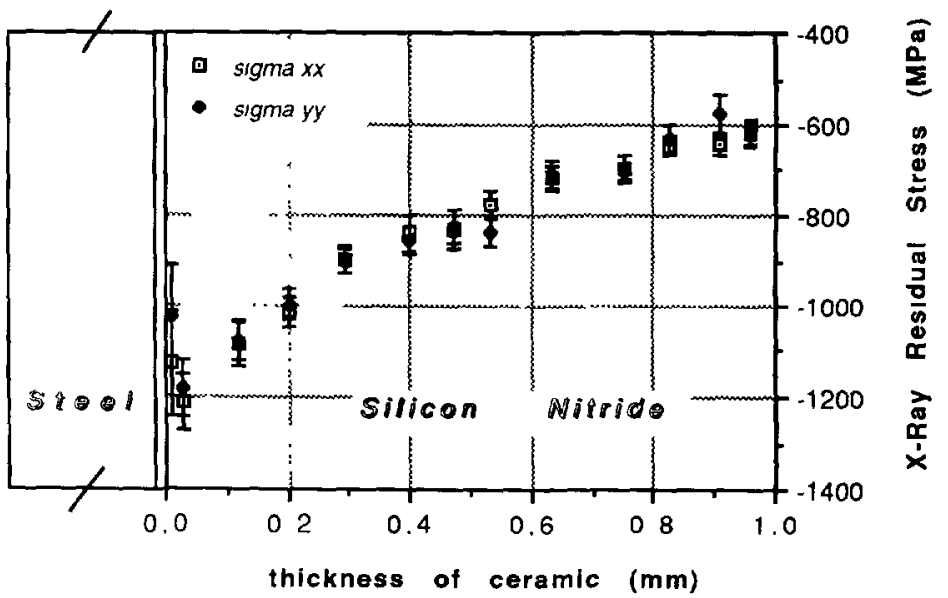

a)

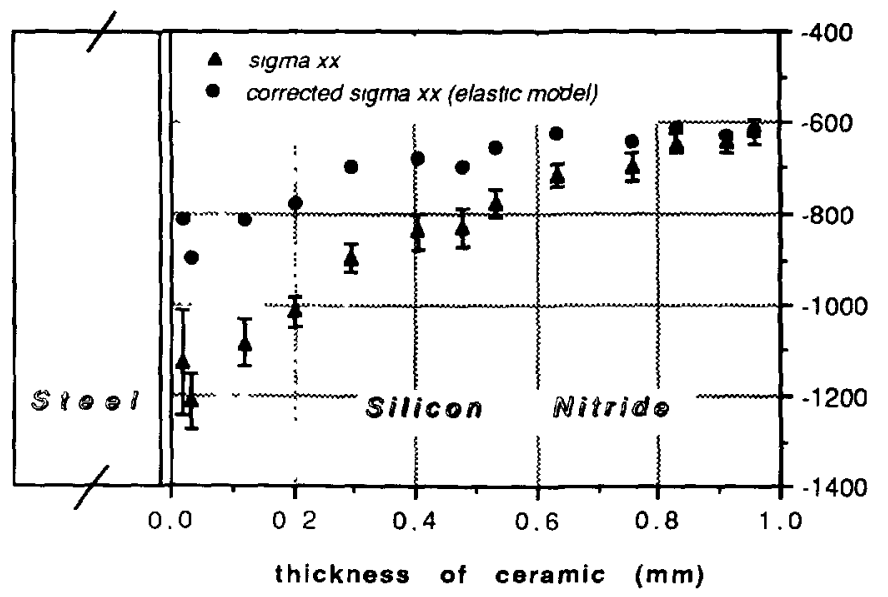

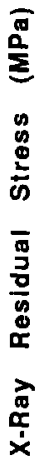

b)

Fig. 8. - X-ray stress measurements in silicon nitride $v s$. distance from the ceramic/steel interface. a) $\sigma_{11}$ and $\sigma_{n}$ stresses as measured, b) $\sigma_{11}$. after relaxation correction.

penetration of copper into alumina is less than $0.02 \mu \mathrm{m}$ after diffusion annealing at $900{ }^{\circ} \mathrm{C}$ during $6 \mathrm{~h}$ ).

Nevertheless the embrittlement of ceramic has also been demonstrated for non reactive systems as in the case of solid-state-bonded $\mathrm{Ag} / \mathrm{Al}_{2} \mathrm{O}_{3}[33,34]$. Alumina toughness falls close to the interface, the decrease being as strong as the annealing time is long (Fig. 10). This loss in toughness appears in a zone corresponding to the penetration depth of silver along alumina grain boundaries measured previously by Badrour [35].

The embrittlement of alumina during diffusion may be due to different causes $[33,34]$ :

- local stresses at grain boundaries and in the ceramic bulk, twisting the lattice, consecutively to the metal segregation or/and diffusion;

- the diffusion of metal along grain boundaries or in bulk leads to the formation of sites where charges can be trapped [36]. This phenomenon can induce a decrease in toughness, as shown by the «the Space Charge Physics » developed by Blaise and Le Gressus [37]. 


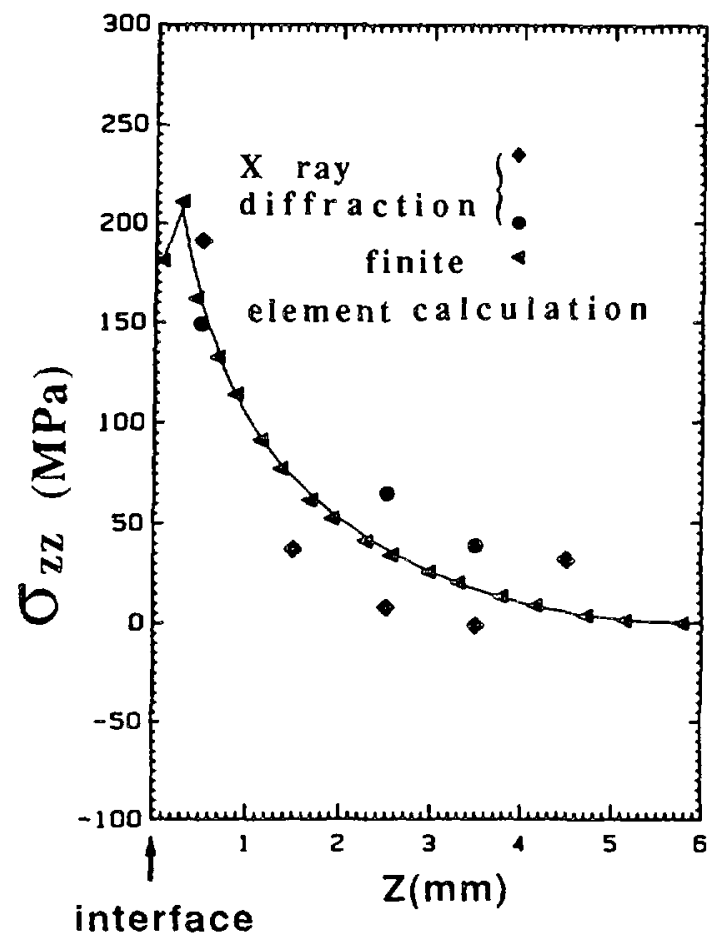

Fig. 9. - X-ray stress measurements in alumına i's. distance from the interface ( $\mathrm{Al}, \mathrm{O}_{\sqrt{ }} /$ Inconel 600 ) (from [25]).

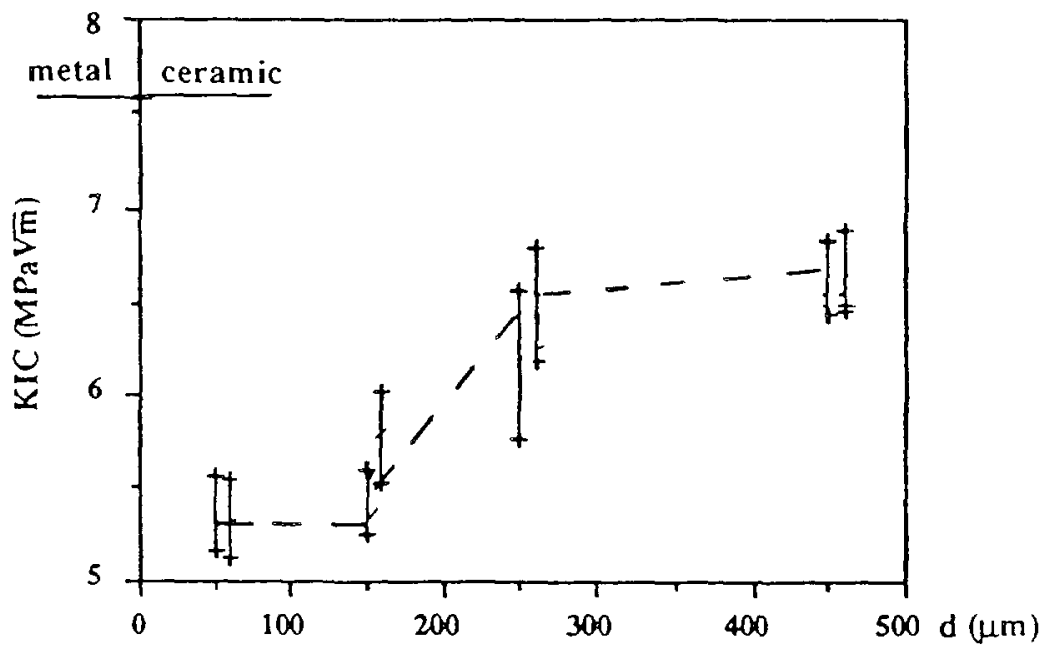

Fig. 10. - Fracture toughness of alumina is. distance from the silver-alumina interface after $192 \mathrm{~h}$ annealing at $900^{\circ} \mathrm{C}[33,34]$. 
3.2 DAMAGES OF BOTH MATERIALS DURING BONDING. - Other damages can be observed during solid state bonding when the applied pressure during elaboration is higher than that required to achieve the full contact between metal and ceramic.

In this way, the metal can damage the ceramic surface or pull out grains of ceramic, by adhesion and sliding [2] (Fig. 11).

On the other hand, the grains of ceramic can scratch the metal, and then become embedded in it (Fig. 12).

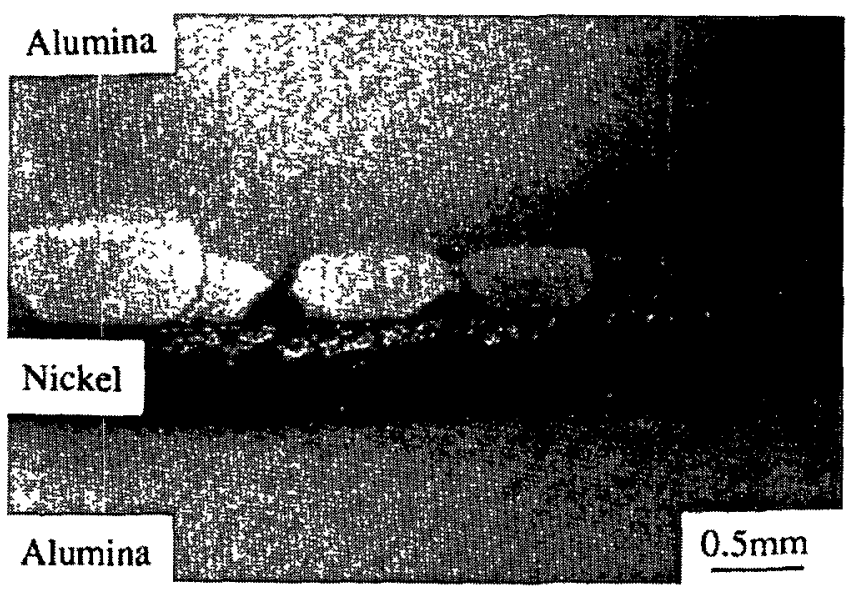

Fig. 11. - Scaling of the ceramic after bonding $\left(\mathrm{Ni} / \mathrm{Al}_{2} \mathrm{O}_{\uparrow}\right)$.

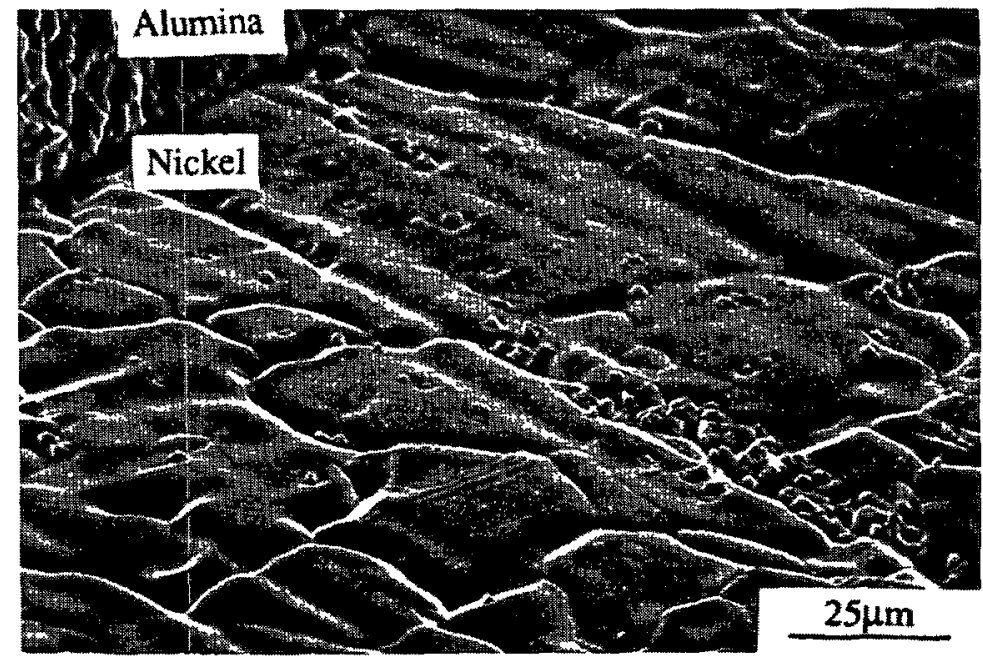

Fig. 12. - Scratches on the nickel surface with embedded alumina grains after sliding of nickel during solid state bonding. 
These flaws, located in the ceramic, near the edges, where high stress concentrations exist, strongly weaken the bonds fabricated at high pressure and high temperature (Fig. 13). The fracture originates from flaws near the interface, especially at the edge of the bond.

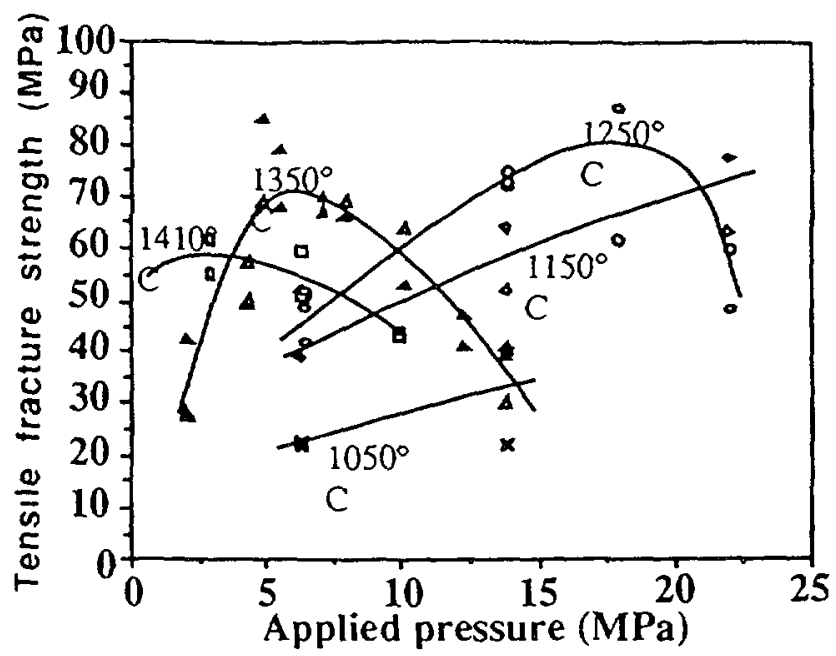

Fig. 13. - Tensile fracture strength of $\mathrm{Ni} / \mathrm{Al}_{2} \mathrm{O}_{3}$ bonds i's. applied pressure at different bondıng temperatures $[2,15]$.

\section{Debonding phenomenon.}

It is quite common to observe a fall in the mechanical properties of a junction after annealings. We shall give two examples of debonding having different origins.

When $\mathrm{Ag} / \mathrm{Al}_{2} \mathrm{O}_{3}$ is solid state bonded in air at $900{ }^{\circ} \mathrm{C}$ using a silver foil saturated with oxygen $(600 \mathrm{ppm})$, the tensile strength reaches about $70 \mathrm{MPa}[33,38]$. Post-annealings in vacuum (or in argon), contrary to annealings in air, lead to a drastic fall in the fracture strength, which become nearly equal to zero for $24 \mathrm{~h}$ annealing at $900^{\circ} \mathrm{C}$ (Fig. 14). Nevertheless, the

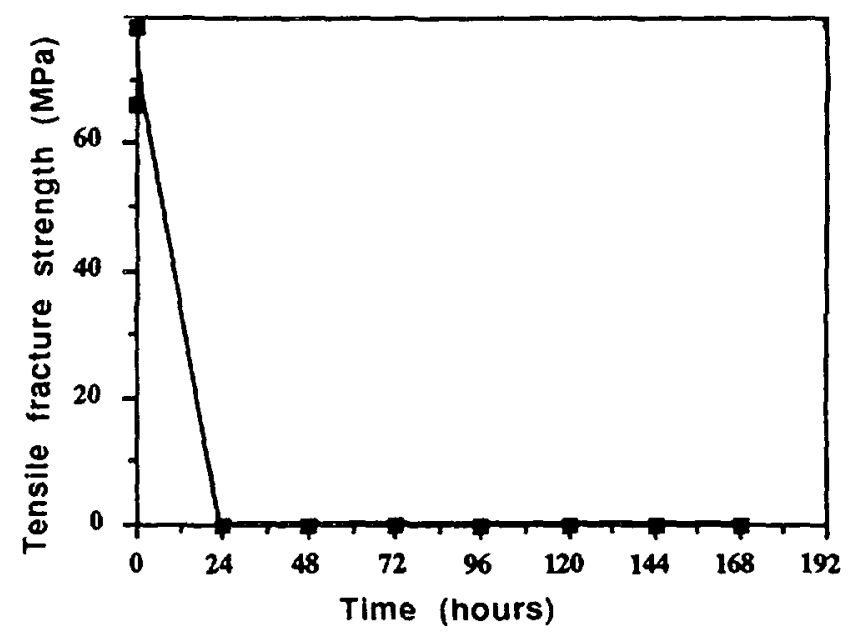

Fig. 14. - Debonding of $\mathrm{Ag} / \mathrm{Al}, \mathrm{O}_{3}$ bonds during anneals at $900^{\circ} \mathrm{C}$ in vacuum. 
bond can be regenerated by a new annealing in air (Fig. 15): it is obvious that oxygen plays an important role in improving the bond strength between $\mathrm{Ag}$ and $\mathrm{Al}_{2} \mathrm{O}_{3}$, probably because of the formation of metal-O clusters [39].

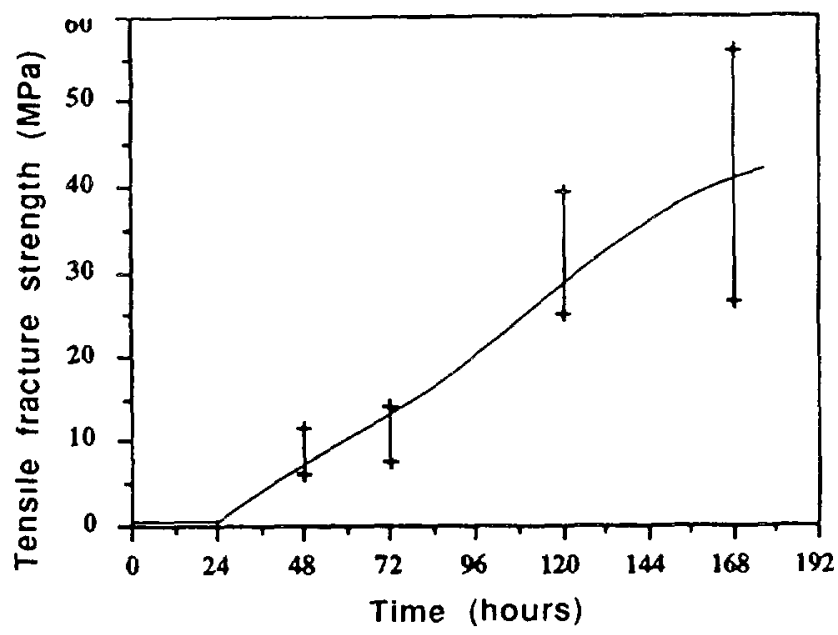

Fig. 15. - Rebondıng in aır at $900{ }^{\circ} \mathrm{C}$ of an $\mathrm{Ag} / \mathrm{Al}_{\curlywedge} \mathrm{O}_{3}$ bond prevıously annealed in vacuum over $168 \mathrm{~h}$.

In the case of the $\mathrm{Ni} / \mathrm{Al}_{2} \mathrm{O}_{3}$ system $[2,15]$ another mechanism explains the debonding shown in figure 16: micrographic and S.E.M. observations, after fracture [2], indicate that the interfacial film, previously evoked, progressively disappears during annealing. Since this film is responsible for high fracture energies (Tab. II), its decrease induces a fall in fracture strength.

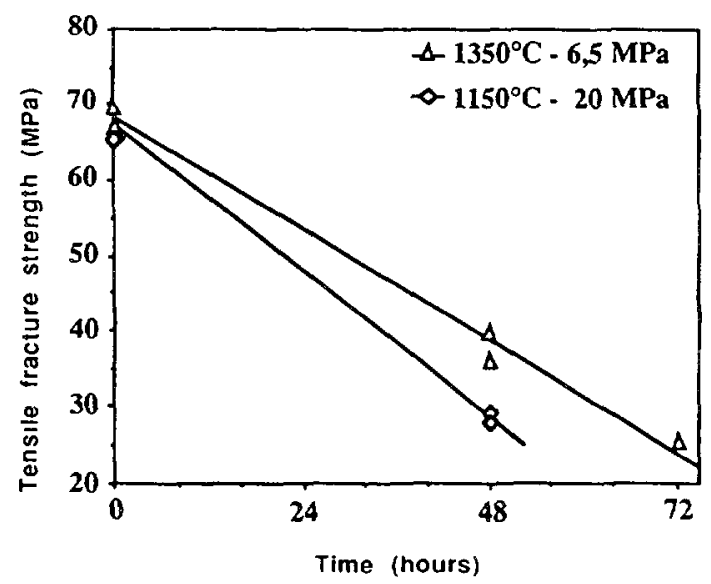

Fig. 16. - Tensile strength of $\mathrm{Ni}_{2} / \mathrm{Al}_{2} \mathrm{O}_{3}$ solid state bonds $\left(1350{ }^{\circ} \mathrm{C}, 6.5 \mathrm{MPa} ; 1150{ }^{\circ} \mathrm{C}, 20 \mathrm{MPa}\right)$ after annealings at $1000^{\circ} \mathrm{C}$ in vacuum. 


\section{Conclusion.}

A complete understanding of the overall metal-ceramic behaviour needs an analysis of a lot of parameters. Have to be taken into account :

From a mechanical point of view' :

- the ratio $\Psi$ between shear and opening mode at interface crack;

- the roughness of the interface;

- the stress field (applied and residual stresses);

- the edge defects, after elaboration, in interface and vicinity (porosities, microcracks, precipitates, pull out of grains, scratches...), especially where the stresses are high ;

- the mechanical properties (yield strength, Young`s modulus, thermal expansion coefficient) of all phases present at the interface, after bonding.

From a physico-chemical point of view :

- the thermodynamic work of adhesion, itself dependent on : chemical bonds, reactive or non reactive elements and interfacial films;

- the change in mechanical properties of materials near the interface, for example, following upon bulk or grain boundary diffusion and storage of polarization energy ;

- the dissipative mechanisms of energy during crack growth, more complex for these systems.

A too limited analysis is consequently doomed to failure if it is not put back in all the physico-chemical and mechanical environment.

\section{References}

[1] Courbière M., Tréheux D., Béraud C., Esnouf C., Ann. Chım. Fr. 12 (1987) 295.

[2] Lourdin P.. Thesis Ecole centrale de Lyon Génie des Matériaux (1992).

[3] Sérier B., Tréheux D., Acta Metall Mater. 41 (1993) 369.

[4] Evans A. G., Hutchinson J. W., Acta Metall 37 (1989) 909.

[5] Rice J. R., J. Appl. Mech 55 (1988) 98.

[6] Dundurs J., J. Appl Mech 36 (1969) 650.

[7] He M. Y., Hutchinson J. W.. J. Appl Mech. (in press).

[8] Gent A. N., Schultz J. S., J. Adhesion 3 (1972) 281.

[9] Jokl M. L., Vitek V., Mahon Mc J., Acta Metall 28 (1980) 1479.

[10] Suo Z., Hutchinson J. W., Mater. Sci. Eng A107 (1989) 135.

[11] Cao H. C., Evans A. G., Mech Mater. (to be published).

[12] Hu M. S., Evans A. G., Acta Met. 37 (1989) 917.

[13] He M. Y., Evans A. G., Acta Metall Mater. 39 (1991) 1587.

[14] Rice J. R., Zhıgang Suo, Wang J. S., Acta Scripta Metall., Proceedings series, vol. 4 (1989) p. 295.

[15] Lourdın P.. Juvé D.. Mater Sci. Forum 126-128 (1993) 711.

[16] Charalambides P. G., Acta Scripta Metall., Proceeding series, 4, M. Rûhle, A. G. Evans Ed. (Pergamon Press, 1989) 383.

[17] Chatain D., Rivollet I., Eustathopoulos N., J. Chım. Phys n 2 (1987) 201.

[18] Evans A. G., Ruhle M., Dalgleish B. J.. Charalambides P. G., Mater Scı. Eng. A126 (1990) 53.

[19] Reimanis I. E., Dalgleish B. J., Evans A. G., Acta Metall Mater. 39 (1991) 3133.

[20] Dubinin E. L., Gushchın S. G., Timofiev A. L., Uzberg L. V., Sov'et non ferrous Metal Res 5 (1976) 151.

[21] Mc Lean M., Hondros E. D., J Mater. Sci. 6 (1971) 19.

[22] Mc Donald J. E., Eberhart J. G., Trans. Metal Soc. AIME 233 (1965) 512.

[23] Gıbbesch B., Elssner G., Acta Metall. Mater. 40 suppl. (1992) S-59. 
[24] Suganuma K., Okamoto T., Koizumi M., Kamachi K., J. Mater. Sci. 22 (1987) 3561.

[25] Colin C., Thesis Ecole des Mines de Paris (1991).

[26] Wittmer M., Boer C. R., Gudmundson P., Carlsson J., J. Am. Ceram. Soc 3 (1982) 149.

[27] Hsueh C. H., Evans A. G., J. Am. Ceram. Soc. 5 (1985) 241.

[28] Batfalsky P., Godziemba-Malızewski J., Lison R., Jouning ceramics, glass and metal. W. Kraft Ed., Information Gesellschaft Verlag (1989) p. 325.

[29] Iancu O. T., Munz D., Joining ceramics, glass and metal, W. Kraft Ed., Information Gesellschaft Verlag (1989) p. 257.

[30] Schmauder S., Acta Scripta Metall. Proc. Series, vol. 4 (Pergamon Press, 1989) p. 413.

[31] Frost H. J., Ashby M. F., Deformation Mechanism Maps (Pergamon Press, Oxford, 1982).

[32] Peytour C., Thesis Université Paris Sud, centre d'Orsay (1989).

[33] Sérier B., Thesis Ecole Centrale de Lyon, Génie des Matériaux (1991).

[34] Sérier B., Berroug A., Juvé D., Moya E. G., J. Europ. Ceram. Soc. 12 (1993) 385.

[35] Badrour L., Thesis Université des sciences d'Aix-Marseille mars (1986).

[36] Berroug A., Fayeulle S., Hamzaoui B., Tréheux D., Le Gressus C., IEEE Trans. Electrical Insulation 28 (1993) 528.

[37] Blaise G., Le Gressus C., C. R Acad Sci. Paris 314 (1992) 1017.

[38] Tréheux D., Juvé D.. Mechanics and Mechanisms of damage in composites and multimaterials. D. Baptıste Ed. (Mechanical Engineering Publications, London, 1991) p. 361.

[39] Kritsalis P., Merlin V., Coudurier L., Eustathopoulos N., Acta Metall. Mater. 40 (1992) 1167. 
Articles Réguliers

Regular Papers 